\title{
Multi-objective ecological reservoir operation based on water quality response models and improved genetic algorithm: A case study in Three Gorges Reservoir, China
}

\author{
Ming $\mathrm{Hu}^{\mathrm{a}, \mathrm{b}}$, Guo H. Huang ${ }^{\mathrm{b}, *}$, Wei Sun ${ }^{\mathrm{c}, * *}$, Yongping $\mathrm{Li}^{\mathrm{b}}$, Xiaowen Ding ${ }^{\mathrm{b}}$, Chunjiang An ${ }^{\mathrm{c}}$, \\ Xiaofei Zhang ${ }^{\mathrm{b}}$, Ting $\mathrm{Li}^{\mathrm{b}}$ \\ a State Key Laboratory of Environmental Aquatic Chemistry, Research Center for Eco-Environmental Sciences, Chinese Academy of Sciences, Beijing 100085, \\ China \\ ${ }^{\mathrm{b}}$ MOE Key Laboratory of Regional Energy Systems Optimization, S-C Resources and Environmental Research Academy, North China Electric Power University, \\ Beijing 102206, China \\ ${ }^{\mathrm{c}}$ Institute for Energy, Environment and Sustainable Communities, University of Regina, Regina, Saskatchewan, Canada S4S 7H9
}

\section{A R T I C L E I N F O}

\section{Article history:}

Received 3 October 2012

Received in revised form

29 March 2014

Accepted 12 July 2014

Available online 23 September 2014

Keywords:

Multi-objective

Operation optimization

Genetic algorithm

Three Gorges

\begin{abstract}
A B S T R A C T
This study proposes a self-adaptive GA-aided multi-objective ecological reservoir operation model (SMEROM) and applies it to water quality management in the Xiangxi River near to the Three Gorges Reservoir, China. The SMEROM integrates statistical water quality models, multi-objective reservoir operations, and a self-adaptive GA within a general framework. Among them, the statistical water quality models of the Xiangxi River are formulated to deal with the relationships between reservoir operation and water quality, which are embedded in constraints of the SMEROM. The multiple objective functions, including maximizing hydropower generation, minimizing loss of flood control, minimizing rate of flood risk, maximizing the average remaining capacity of flood control and maximizing the benefit of shipping, are considered simultaneously to obtain comprehensive benefit among the environment, society and economy. The weighting method is employed to convert the multiple objectives to a single objective. To solve the complex SMEROM, an improved self-adaptive GA is employed through incorporating simulated binary crossover and self-adaptive mutation. To demonstrate the advantage of the developed SMEROM model, the solutions through ecological reservoir operation are compared with those through the traditional reservoir operation and the practical operation in 2011, in terms of water quality, reservoir operation and objective function values. The results show that most of benefit in the ecological operation is better than that in the traditional or practical operations except for the hydropower benefit and loss benefit of flood control. This is because flood control and environmental protection are reasonably considered in the ecological operation.
\end{abstract}

(c) 2014 Elsevier Ltd. All rights reserved.

\section{Introduction}

Reservoirs are common elements of the cultural landscape worldwide, which have mostly been built by the damming of rivers (Krolová et al., 2012). Reservoir operation facilitates flood control, agriculture irrigation, hydropower generating, and shipping (Wang et al., 2006), which serves human by optimizing benefit through meeting societal demand but often ignoring environmental sustainability (Mukand et al., 2012). In fact, the damming results in significant changes to the river ecological environment. For example, water recreational activities cut

\footnotetext{
* Corresponding author. Tel.: + 1061773889; fax: +1061773885.

*** Corresponding author.

E-mail addresses: huang@iseis.org (G.H. Huang), sunwei@iseis.org (W. Sun).
}

down the space for aquatic organisms (Jiang et al., 2006a, 2006b; Rohdea et al., 2006); water transfer projects change the spatial and temporal pattern of regional water resources (Zeilhofer and Rubem, 2009;); and reservoirs aggravate the degradation of water quality and the spread of water-borne diseases (Mukand et al., 2011; Lu et al., 2012). Considering these changes, modern reservoir management demands a new paradigm, which integrates ecological components into its management decisions (Camdevyren et al., 2005; Suen and Eheart, 2006; Cabecinha et al., 2009; Chen et al., 2011).

Ecological reservoir operation involves complex decision making processes with multiple decision variables and objectives as well as considerable risk (Mehrdad et al., 2010). In nature, ecological reservoir operation is a multi-objective optimization problem (MOP). These objectives may be conflicting and incommensurable 
while different groups of people or interests may be interacted (Chen et al., 2007). During the past decades, a variety of methods have been developed to solve the MOP (Mehrdad et al., 2010; Labadie, 2004). For example, Chen et al. (2007) proposed a diversified multi-objective Genetic Algorithm (GA) for optimizing reservoir rule curves. Chang et al. (2010) developed constrained genetic algorithms for optimizing multi-use reservoir operation. Wang et al. (2011) showed multi-tier interactive GAs for the optimization of long-term reservoir operation. Yin and Yang (2011) developed a coupled reservoir operation and water diversion model, which balanced human and environmental flow requirements. Mukand et al. (2011) studied a reservoir operation simulation to analyze the impact of hydropower system operation in alternative scenarios on energy production and natural flow regime in the La Nga river basin in Vietnam.

Although multiple objectives could be dealt with effectively, it is still necessary to incorporate the detrimental effects of reservoirs and the related environmental requirement within the reservoir operation framework. Some work illustrated the impact of reservoir operation on the water quality (Yandamuri et al., 2006; HakimiAsiabar et al., 2010; Castelletti et al., 2012). Most of the above methods dealt with the water quality problem by simulation models instead of statistical models (Camdevyren et al., 2005; Cabecinha et al., 2009; Li et al., 2011; Chen et al., 2011). Few studies directly relating water-quantity control measures to water quality have been found. The statistical model is a useful method to directly quantify the detrimental effects of reservoirs based on the relationships between reservoir operation and water quality responses. Various multivariable statistical approaches have been widely used to explore spatial and temporal variations, which are capable of obtaining relationship through reducing the dimensionality of datasets (Singh et al., 2005; Li et al., 2010a, 2010b, 2011). Thus, it is desired a statistical water quality response model should be embedded in water quality constraints within the reservoir operation management framework (Han et al., 2012).

When the water quality response model is incorporated in a MOP model, its solution would become more difficult (Yeh and Becker, 1982; Chen et al., 2007). With development of intelligent computation, evolutionary algorithms become very efficient in dealing with MOP due to their population-based nature (Cai et al., 2001; Huang et al., 2002; Kerachian and Karamouz, 2007; Tripathi and Pal, 2007; Chaves and Chang, 2008; Chen and Chang, 2009). In recent years, multi-objective evolutionary algorithms have been applied in reservoir operation problems (Janga Reddy and Nagesh Kumar, 2006, 2007; Hakimi-Asiabar et al., 2008; Chang, 2008; Han et al., 2012). It is shown that real-coded GAs are more suitable for large dimensional search spaces than binary-coded GAs, since they are more consistent and accurate, and they generate faster convergence (Kancev et al., 2011). The weighting method was employed to translate multiple objectives to a single objective, which was obtained from the weighted sum of the original multiple objectives (Chen et al., 2007). In order to improve the efficiency of GA, the self-adaptive characteristic was incorporated in the real-coded GA by using special mutation operators and crossover operators, such as simulated binary crossover (SBX), which create offspring statistically located in proportion to the difference of the parents in the searching space (Deb and Beyer, 1999; Su and Chiang, 2004; Subbaraj et al., 2011). Although the conventional GA has been improved in various aspects, few GA was designed to solve a MOP for ecological reservoir operation.

Therefore, the objective of this study is to develop a selfadaptive GA-aided multi-objective ecological reservoir operation model (SMEROM) and apply it to water quality management in the Xiangxi River (XXR) near to the Three Gorges Reservoir (TGR) in China, which is the largest and most representative hydropower project all over the world. The SMEROM will directly incorporate statistical models in constraints to reflect the relationships between reservoir operation and water quality; it possesses the excellent attributes of self-adaptive evolutionary algorithms for solving the corresponding complicated MOP; and it will help decision-makers evaluate alternative operating rules efficiently. The optimized solutions through the ecological reservoir operation will be compared with those through the traditional and the practical operation in 2011.

\section{Methodology}

\subsection{Framework}

A multi-objective ecological reservoir operation problem can be described as finding a vector of decision variables that satisfies the constraints of environment and optimizes a vector function of economic interest whose elements represent the objective functions. These functions result from the mathematical description of performance criteria, and in most cases are in conflict with each other (Chen et al., 2007). To deal with the problem, the developed SMEROM consists of: (1) establishing a statistical water quality model by using multiple linear regression in order to find the response dependence of water quality on reservoir operation, which is embedded in water quality constraints related to total nitrogen concentrations (TN), total phosphorus concentrations (TP) and the density of algal cell (DA) in Xiangxi river (the river is the largest tributary in the Hubei portion of TGR); (2) developing a multi-objective ecological reservoir operation model for predicting the different function value under various constraints in order to maximize the overall benefit of reservoir operation; (3) improving the traditional genetic algorithm by self-adaptive crossover operators and self-adaptive mutation operators, real-coded and weighting method; (4) integrating the statistical water quality model and self-adaptive GA to the SMEROM framework. The components of the SMEROM model are described in detail in the following sections.

\subsection{The statistical water quality model of XXR}

Many factors affect the water quality of reservoir, such as pollution sources, temperature, physico-chemical properties of the water mass as well as interactions among these physical, chemical and biological components of the system. To improve water quality, a response model between water quality and reservoir operation has been established to deal with the water quality problems caused by reservoir. Pearson correlation analysis is conducted between reservoir operation and water quality index, respectively. The multiple linear regression analysis is conducted between reservoir operation and three water quality indexes (TN, TP and DA) in the Xiangxi River. The three regression equations between reservoir operation and water quality indexes are constructed respectively as follows:

$$
\begin{aligned}
& \operatorname{DA}(Y)=a_{1}+b_{1} x_{1}+b_{2} x_{2}+b_{3} x_{3}+e_{1} \\
& \operatorname{TN}(Y)=a_{2}+c_{1} x_{1}+c_{2} x_{2}+c_{3} x_{3}+e_{2} \\
& \operatorname{TP}(Y)=a_{3}+d_{1} x_{1}+d_{2} x_{2}+d_{3} x_{3}+e_{3}
\end{aligned}
$$

where $a_{k}$ is a constant term; $b_{k}, c_{k}$ and $d_{k}$ are the regression coefficients; $x_{k}$ is the value related to reservoir operation ( water release, water head and inflow) and $e_{k}$ is the error term of the model. 


\subsection{Multi-objective ecological reservoir optimal operation model}

In a MOP, many objective functions need to be optimized simultaneously. Without loss of generality, the MOP with $r$ minimum objectives and several constraints can be mathematically stated as follows (Li et al., 2010a, 2010b):

$\min F(X)=\min \left\{f_{1}(X), f_{2}(X), \ldots, f_{r}(X)\right\}$

Subject to:

$g_{i}(X) \leq 0 \quad i=1,2, \ldots, l$

$h_{j}(X)=0 \quad j=1,2, \ldots, m$

$X_{k}^{l} \leq X_{k} \leq X_{k}^{u} \quad k=1,2, \ldots, n$

where $X$ is the decision vector; $f_{r}(X)$ is the $r$ th objective function; $F(X)$ is the objective vector; $g_{i}(X)$ is the $i$ th inequality constraint; $h_{j}(X)$ is the $j$ th equality constraint; $X_{k}^{l}$ and $X_{k}^{u}$ are lower and upper bounds for decision variable $X_{k}$.

Obviously, model (2) is a traditional multi-objective reservoir operation model without considering the environmental requirement, so that it cannot deal with the environmental or ecological problems during the reservoir operation. Moreover, solving multiple objectives simultaneously would reduce the running speed of GAs, so some certain processing should be applied.

In this paper, the weighting method is employed to translate the multiple objectives to a single objective, which is obtained from the weighted sum of the original multiple objectives (Chen et al., 2007). The environmental or ecological constraints are embedded in the traditional operation model, so a multiobjective ecological reservoir operation model can be formed as follows:

$\min F(X)=\omega_{1} f_{1}(X)+\omega_{2} f_{2}(X)+\cdots+\omega_{r} f_{r}(X)$

Subject to:

$g_{i}(X) \leq 0 \quad i=1,2, \ldots, l$

$h_{j}(X)=0 \quad j=1,2, \ldots, m$

$L_{S}(X) \leq R_{S} \quad s=1,2, \ldots, t$

$\sum_{z=1}^{r} \omega_{z}=1 \quad z=1,2, \ldots, r$

$X_{k}^{l} \leq X_{k} \leq X_{k}^{u} \quad k=1,2, \ldots, n$

where $L_{s}(X)$ is the sth statistical water quality constraint; $R_{S}$ is the water quality requirement; $\omega_{z}$ is the weight of $z$ th objective function. Model (3) integrates the statistical water quality model into the traditional multi-objective reservoir optimal operation model, which can consider the environmental requirement during the reservoir operation. Model (3) will be solved through an improved genetic algorithm.

\subsection{Genetic algorithms}

The genetic algorithm (GA) was proposed by John Holland (Holland, 1975), and has been broadly utilized to solve different optimization problems. The GA simulates some processes observed in natural evolution. It starts with a randomly generated initial population of a string of variables known as chromosomes which hold the parameters, genes and the size of population. Some operators including scheme selection (reproduction), crossover and mutation, would be implemented in order to improve the fitness of solutions through iterations. The chromosome can be represented with binary or decimal code, so the corresponding GA is termed as binary-coded or real-coded GA. In selection operator, a set of chromosomes are selected as initial parents at the reproduction stage on the basis of their fitness. The process of mating is implemented through the crossover operator. Mutation, an arbitrary change of the genes, is implemented to preserve the genetic diversity in the population. Mutation probability of occurrence should be kept low as it would potentially disrupt the good solution (Chien and Wang, 2011). The stochastic selection process, biased towards the fitter individuals, is implemented to select the new set of population for the next generation. The newly created population is further evaluated and tested for termination. If the termination criterion is not met, the population is iteratively operated and evaluated further by the above three operators until termination criterion of pre-set maximum number of generations is met (Ahmed and Sarma, 2005; Vascan and Raju, 2009).

More recently, GA has been applied to the search for multiobjective optimization, which has the distinct advantage of being able to handle multi-objective problems that other gradient-based optimizers have failed to solve (Augusto et al., 2006). For example, Chang (2008) proposed proper penalty strategy for every parameter in order to guide GA searching process, which is used as a search engine for reservoir flood operation; Hakimi-Asiabar et al. (2009) showed the concept of learning rule of Self-Organizing Map (SOM), which can learn and improve the efficiency of data processing algorithms, with the purpose of improving the genetic diversity; Hakimi-Asiabar et al. (2010) developed a Self-Learning Genetic Algorithm (SLGA) model and applied the model to derive optimal operating policies for a threeobjective multi-reservoir system; Han et al. (2012) employed a selfadaptive genetic algorithm with simulated binary crossover to search optimal reservoir operating rules. The GA seems particularly suitable for solving multi-objective optimization problems because it deals simultaneously with a set of possible solutions. This allows the identification of several members of the Pareto-optimal set in a single run, in contrast to traditional mathematical programming techniques. Although the GA is efficient in searching for globally optimal solutions, it still encounters the difficulties in dealing with complex constraints. One difficulty is that once the search has narrowed near the previous optimal solution, the diversity in the population may not be enough for the search to come out and proceeds towards the new optimal solution. Furthermore, mutation probability of occurrence can potentially disrupt the good solution. Therefore, some improvements should be implemented to obtain better GA solutions.

\section{Case study}

\subsection{Study area}

The Yangtze River is $6300 \mathrm{~km}$ long, which has a catchment area of $1.96 \times 10^{6} \mathrm{~km}^{2}$ and an annual water discharge of $9.8 \times 10^{11} \mathrm{~m}^{3}$ (Hu and Cai, 2006; Fu et al., 2010; Zeng et al., 2010). The Three Gorges Dam (TGD) is the largest hydro-electric dam in the world, more than $1.5 \mathrm{~km}$ wide across the Yangtze River. It is designed to help control flood and enhance shipping in the Yangtze River, and perhaps more importantly increases energy supply for China's rapid economic development. The dam is a concrete gravity type with a height of $185 \mathrm{~m}$, total water storage capacity of 39.3 billion $\mathrm{m}^{3}$ and flood control capacity of 22.1 billion $\mathrm{m}^{3}$, which increases the flood control ability from the present 10 -year to a 100-year frequency flood (Zhang and Lou, 2011). It is by far the world's largest hydro-electric system, comprising a dam, two powerhouses and shipping facilities, which has installed a total generating capacity of 22,400 MW (100 billion kWh), equivalent to consumption of more than 60 million tons of raw coal annually. Moreover, the dam effectively enhances the shipping in the $600 \mathrm{~km}$ section of the Yangtze River between Yichang and Chongqing through increasing water depth by more than $100 \mathrm{~m}$. 
After the completion of the TGD, a $600 \mathrm{~km}$-long reservoir (Three Gorges Reservoir) has been formed. The Three Gorges Reservoir (TGR) $\left(29^{\circ} 16^{\prime}-31^{\circ} 25^{\prime} \mathrm{N}, 106^{\circ}-110^{\circ} 50^{\prime} \mathrm{E}\right)$ is located in the subtropical monsoon climate prevailing zone, with an average annual rainfall of 1000-1300 mm (Huang et al., 2006; Jiang et al., 2006a, 2006b). The reservoir has a capacity of $3.93 \times 10^{10} \mathrm{~m}^{3}$ and a water level of $175 \mathrm{~m}$, covering a surface area of $1080 \mathrm{~km}^{2}$ and watershed area of over $1.00 \times 10^{6} \mathrm{~km}^{2}$. Fig. 1 shows the study area. There are 40 large reservoir bays formed, and the total area of these bays accounts for $1 / 3$ of the whole surface area of the TGR (Cai and Hu, 2006; Huang et al., 2006). After the first experimental impounding in 2008, the water level regime of TGR changed drastically, with a fluctuation from $172.8 \mathrm{~m}$ on November 10 to $144.7 \mathrm{~m}$ on June 9. The construction period of the Three Gorges Project (TGP) can be divided into three stages: the preparation and first stage (1993-1997), the second stage (1998-2003) and the third stage (2004-2009). After the completion of TGP, the water level will fluctuate between $175 \mathrm{~m}$ (rainy season) and $145 \mathrm{~m}$ (dry season) while the current water level in 2011 is approximately $170 \mathrm{~m}$ (Cao et al., 2011).

While the benefit of TGP is indeed substantial, the environmental impacts of TGP on the Yangtze River ecosystems cannot be neglected (Chen, 2004; Huang, 2004). The environmental impacts affect many river-related ecosystem components, such as hydrology, water quality, sediment regime, and both aquatic and terrestrial flora and fauna, on account of the tremendous size of the dam and its strategic position at $1830 \mathrm{~km}$ upstream from the mouth of the Yangtze River (Tullos, 2009).
After the impounding of TGR, the flow speed in some tributaries located in the reservoir became very slow (some were below $0.05 \mathrm{~m} / \mathrm{s}$ ), which weaken the water exchange in the vertical direction and lead to the deposition of nutrient and silt (Deng and Gong, 2007; Li et al., 2007; Zheng et al., 2008). As a result, the phytoplankton in the water may grow quickly, and an "algae bloom" may be triggered by suitable temperature, sunshine, air velocity and other biological factors (Kong and Fao, 2005). A lot of algae blooms, predominantly dinoflagellates and diatoms, have been observed, especially during the spring dry season, since the inundation of TGP in 2003 (Cai and Hu, 2006). The eutrophication has become the main water environmental problem and is now attracting more and more attention worldwide (Dai et al., 2010; Yang et al., 2010).

Solving the environmental challenges surrounding the TGD would be essential for the sustainable development of the Three Gorges Reservoir Region (TGRR) and remains a high priority for the country as well. However, any efforts will have to rely on the determination of the environmental changes due to the construction of the TGD. The challenge has never been greater than now. Moreover, the operation of the reservoir is a multi-objective problem, which increased the complexity of the problem of operation reservoir in one way. In this paper, a self-adaptive GA multi-objective ecological reservoir operation model (SMEROM) was developed to deal with the above problems. The details of the SMEROM would be discussed in the following section. Table 1 shows the abbreviations and their full names used in this paper.

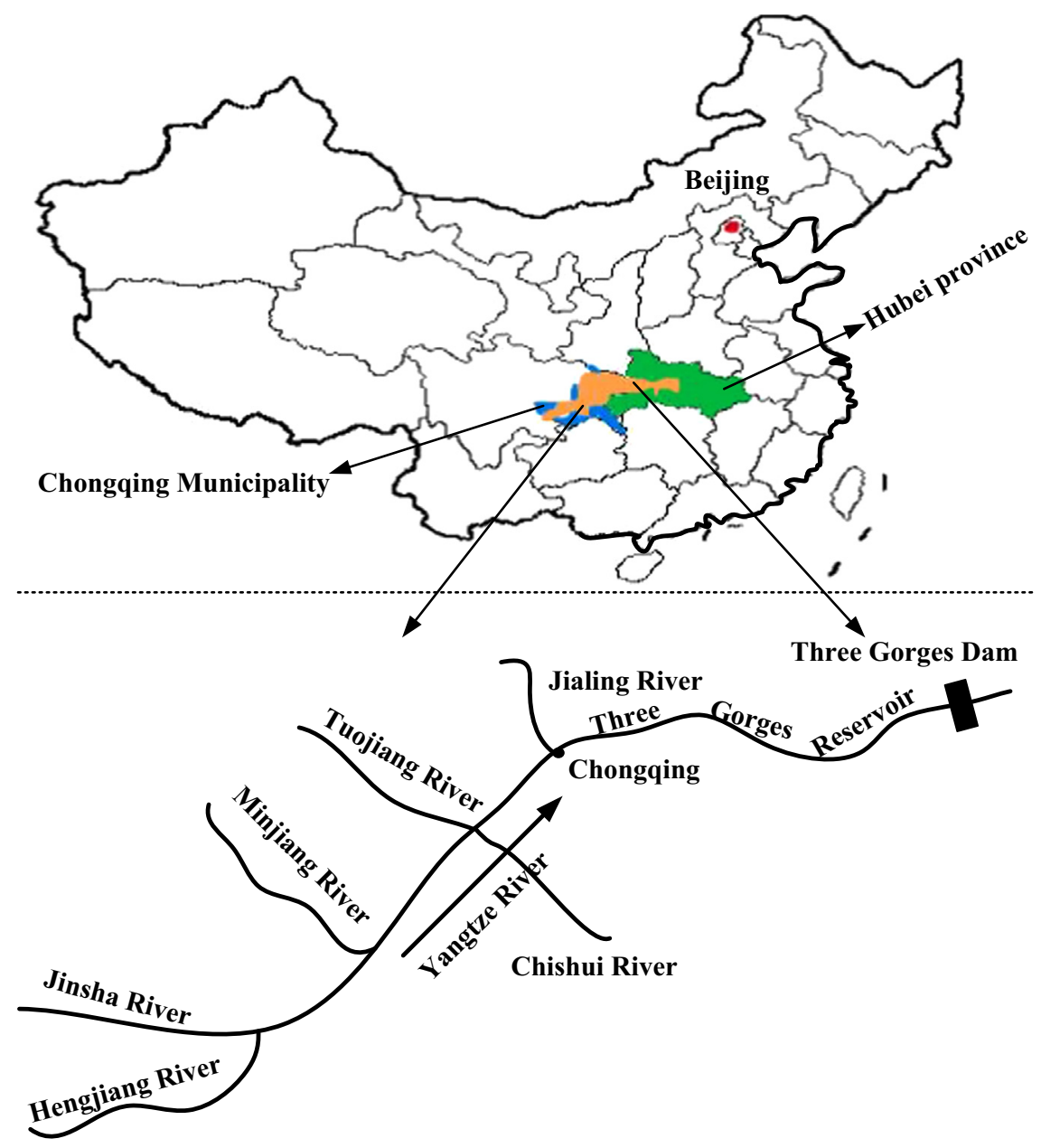

Fig. 1. The study area. 
Table 1

The abbreviations and their full names.

\begin{tabular}{ll}
\hline Abbreviation & Full name \\
\hline GA & Genetic algorithm \\
SMEROM & Self-adaptive GA-aided Multi-objective Ecological Reservoir Operation Model \\
MOP & Multi-objective optimization problem \\
SBX & Simulated binary crossover \\
XXR & Xiangxi river \\
TGR & Three Gorges Reservoir \\
TN & Total nitrogen concentrations \\
TP & Total phosphorus concentrations \\
DA & Density of algal cell \\
SOM & Self-organizing map \\
SLGA & Self-learning genetic algorithm \\
TGD & Three Gorges dam \\
TGP & Three Gorges project \\
TGRR & Three Gorges Reservoir region \\
SPSS & Statistical product and service solution \\
\hline
\end{tabular}

\subsection{Data collecting and sorting}

(1) The data of inflow.

The Yichang station gives a total of 130 years (1878-2007) of historic inflow data. A 10-day period, the traditional time frame in Chinese agricultural society, is used as a time step. The inflow data, which is input of the optimized model, can be obtained by statistical analysis according to the available historic inflow data. Table 2 show the inflow volume to the TGR in 2012, which would be served as the input of the developed model.

(2) The data of reservoir.

The data of water level, water storage, water release and water head loss in TGR were collected and analyzed with statistical product and service solution (SPSS). In this study, the relationship between water level and reservoir water storage, the relationship between tail water level and water release, and the relationship between inflow and head loss, have attained their regression equation according to the SPSS. Fig. 2 shows the fitting curves (2a) between the water level and water storage, (2b) between the tail water level and water release and $(2 \mathrm{c})$ between the inflow and head loss, respectively.

(3) The data of water quality index.

The Xiangxi River (XXR) is the largest tributary in the Hubei portion of TGR. The phenomenon of water degradation occurred frequently in the Xiangxi Bay after the impounding of the TGR in 2003. The observed data of water quality index from 2000 to 2010, such as TN, TP and DA, related with XXR have been collected for multiple regression analysis, so that the statistical water quality model can be obtained and used for constraints of the developed model.

\subsection{Reservoir operation formulation}

\subsubsection{Objective functions}

The proposed SMEROM model has five different objective functions, which are mainly derived from the references (Wang et al., 2004; Liu et al., 2004; Dong et al., 2007). The first objective function is the benefit of hydropower generation (Wang et al., 2004; Liu et al., 2004); the second to fourth objective functions are the flood control objectives during the TGR operation (Liu et al., 2004, 2006, 2007); and the fifth objective function is the benefit of shipping (Liu et al., 2006; Dong et al., 2007).
Table 2

Inflows to the TGR in 2012

\begin{tabular}{lllllllr}
\hline Period & $\begin{array}{l}\text { Inflow } \\
\left(\mathrm{m}^{3} / \mathrm{s}\right)\end{array}$ & Period & $\begin{array}{l}\text { Inflow } \\
\left(\mathrm{m}^{3} / \mathrm{s}\right)\end{array}$ & Period & $\begin{array}{l}\text { Inflow } \\
\left(\mathrm{m}^{3} / \mathrm{s}\right)\end{array}$ & Period & $\begin{array}{l}\text { Inflow } \\
\left(\mathrm{m}^{3} / \mathrm{s}\right)\end{array}$ \\
\hline 1 & 4644 & 10 & 5490 & 19 & 28,674 & 28 & 22,350 \\
2 & 4311 & 11 & 6651 & 20 & 31,470 & 29 & 19,119 \\
3 & 4075 & 12 & 7992 & 21 & 30,099 & 30 & 15,985 \\
4 & 3927 & 13 & 9757 & 22 & 28,206 & 31 & 12,608 \\
5 & 3919 & 14 & 11,706 & 23 & 28,050 & 32 & 10,234 \\
6 & 4080 & 15 & 13,528 & 24 & 26,934 & 33 & 8212 \\
7 & 4254 & 16 & 14,799 & 25 & 27,570 & 34 & 6962 \\
8 & 4410 & 17 & 17,297 & 26 & 26,136 & 35 & 5922 \\
9 & 4736 & 18 & 23,412 & 27 & 24,291 & 36 & 5176 \\
\hline
\end{tabular}

\subsubsection{Maximizing hydropower generation.}

$\operatorname{Max} f_{1}=\sum_{i=1}^{36} \kappa \alpha Q_{i} H_{i} T_{i}$

$H_{i}=Z_{\text {up }}\left(Q_{i}\right)-Z_{\text {down }}\left(Q_{i}\right)-Z_{\text {loss }}$

$Z_{\text {up }}\left(Q_{i}\right)=78.65+\sqrt{23.288\left[V_{i}+\left(I_{i}-Q_{i}\right) \times T_{i}\right]+127.225}$

$Z_{\text {down }}\left(Q_{i}\right)=62.57917+9.84891 \times 10^{-5} Q_{i}+1.42007 \times 10^{-9} Q_{i}^{2}$

$Z_{\text {loss }}=\left\{\begin{array}{ll}1 \times 10^{-4} I_{i} & 5000 \mathrm{~m}^{3} / \mathrm{s} \leq I_{i} \leq 10,000 \mathrm{~m}^{3} / \mathrm{s} \\ 1 \times 10^{-5} I_{i}+0.9 & 10,000 \mathrm{~m}^{3} / s \leq I_{i} \leq 60,000 \mathrm{~m}^{3} / \mathrm{s}\end{array}\right\}$

where $f_{1}$ is the function of hydropower generation; $i$ is the number of period ( 10 days); $\kappa$ is the price of hydropower (0.2506 RMB/ KW H); $\alpha$ is the output factor, and $\alpha=9.81 \eta=8.5, \eta$ is the efficiency coefficient of hydropower plant (Liu et al., 2004); $Q_{i}$ is the water release in the $i$ th period; $H_{i}$ is the water head in the $i$ th period which is usually a nonlinear function; $T_{i}$ is the generating duration in the $i$ th period; $Z_{\text {up }}\left(Q_{i}\right)$ shows the relationship between water level and water release; $Z_{\text {down }}\left(Q_{i}\right)$ shows the relationship between tail water level and water release; $Z_{\text {loss }}$ is the head loss; $V_{i}$ is the reservoir water storage in the $i$ th period; $I_{i}$ is the inflow in the $i$ th period. According to the collected data in the TGR, the fitting curves (Fig. 2) can be obtained. So models (6), (7) and (8) can be obtained according to Fig. 2a-c, respectively. And the relationships have been discussed in Section 3.2. 

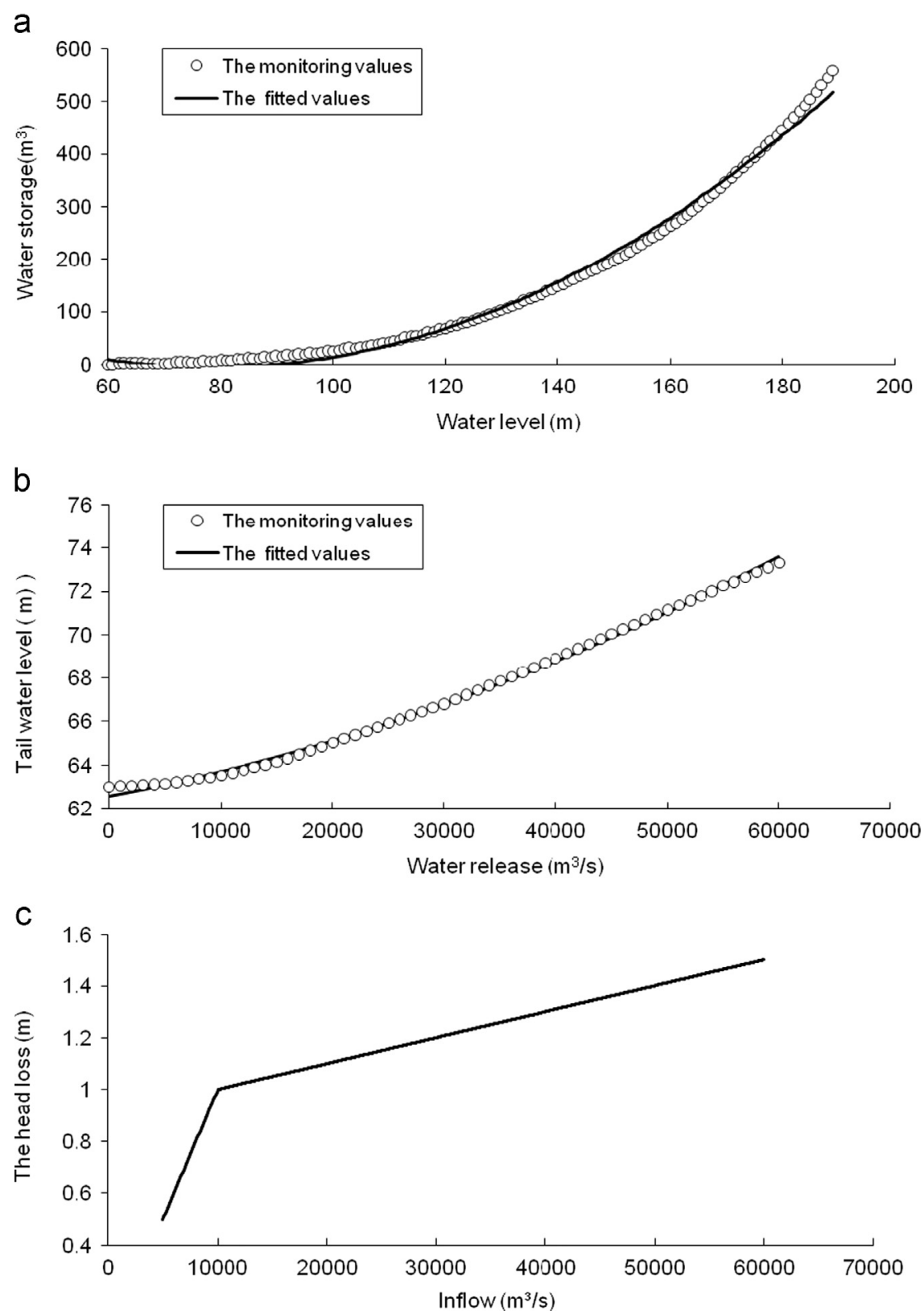

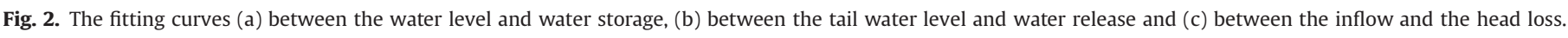

\subsubsection{Minimizing loss of flood control.}

Min $f_{2}=\sum_{i=1}^{36} R_{i} K_{1} Q_{i}^{K_{2}}$

where model (9) comes from the curve fitting according to frequently-used essential nonlinear model (SPSS), combined with other methods such as theoretical analysis and scatter diagrams. The curve, between economical loss and water release, was selected by high coefficients of determination and considering the theoretical knowledge of flood. $R_{i}$ is a $0-1$ value related with water release according to the regulation rule of TGR operation; $K_{1}$ and $K_{2}$ are the loss coefficients of flood control $\left(K_{1}=0.00985\right.$, $K_{2}=0.758$ ) according to the curve.

\subsubsection{Minimizing rate of flood risk.}

$\operatorname{Min} f_{3}=\frac{1}{36} \sum_{i=1}^{36} R_{i}$
$R_{i}= \begin{cases}1 & \left(Q_{i}>35,000 \mathrm{~m}^{3} / \mathrm{s}\right) \\ 0 & \left(Q_{i} \leq 35,000 \mathrm{~m}^{3} / \mathrm{s}\right)\end{cases}$

3.3.1.4. Maximizing the average remaining capacity of flood control.

$\operatorname{Max} f_{4}=\overline{V_{f}}=\frac{1}{K} \sum_{n=1}^{K}\left(V_{Z n}-V_{n}\right)$

where $n$ is the number of flood $(n=1,2, \ldots, \mathrm{K}) ; \overline{V_{f}}$ is the average remaining capacity of flood control under normal storage level $(175 \mathrm{~m}) ; V_{Z n}$ is the reservoir water storage corresponding to normal storage level (175 m); $V_{n}$ is the maximal applied capacity of flood control during the $n$th flood operation according to model (24).

3.3.1.5. Maximizing the benefit of shipping.

$\operatorname{Max} f_{5}=\frac{1}{36} \sum_{i=1}^{36} S_{i}$ 
$S_{i}= \begin{cases}1 & 145 \mathrm{~m} \leq Z_{\text {up }} \leq 175 \mathrm{~m}, 62 \mathrm{~m} \leq Z_{\text {down }} \leq 73.8 \mathrm{~m} \\ 1 & 5000 \mathrm{~m}^{3} / \mathrm{s} \leq Q \leq 56,700 \mathrm{~m}^{3} / \mathrm{s} \\ 0 & Z_{\text {up }} \leq 145 \mathrm{~m}, Z_{\text {up }} \geq 175 \mathrm{~m}, Z_{\text {down }} \leq 62 \mathrm{~m}, \quad Z_{\text {down }} \geq 73.8 \mathrm{~m} \\ 0 & Q \geq 56,700 \mathrm{~m}^{3} / \mathrm{s}, \quad Q \leq 5000 \mathrm{~m}^{3} / \mathrm{s}\end{cases}$

where $S_{i}$ is a $0-1$ value which reflects the navigable condition according to the navigable regulation rule of TGR (Liu et al., 2004). The navigable conditions of TGR can be divided into three categories: the water level belongs to $[145,175] \mathrm{m}$; the tail water level belongs to $[62.0,73.8] \mathrm{m}$; and the maximal water release belongs to [5000, $56,700] \mathrm{m}^{3} / \mathrm{s}$. As shown in model (14), when the navigable condition of the TGR meets the above three categories, the ship can pass the TGR smoothly.

\subsubsection{Constraints}

3.3.2.1. The constraints of water quality. According to the available data for water quality indexes (DA, TN and TP) in Xiangxi River (XXR), the multiple linear regression analysis is conducted between reservoir operation and three water quality indexes, respectively (Mukhopadhyay et al., 2000; Maillard and Santos, 2008). All the statistical procedures are conducted by using SPSS 15.0 for Windows. The process of regression analysis contained all parameters. However, for the stepwise regression equation, significant variables were contained step by step during the course of regression according to the setting standards while insignificant variables were excluded, and the regression was not completed until there were no more additions or exclusions (Liu et al., 2008). The three regression equations are constructed respectively as follows.

\subsubsection{The constraints of $D A$.}

$\mathrm{DA}_{i}=11,730,000+700784.427 H_{i}-2349.326 I_{i}+3191.871 Q_{i} \leq \mathrm{RDA}_{i}, \quad \forall i$

3.3.2.3. The constraints of $T N$.

$\mathrm{TN}_{i}=0.061 H_{i}+0.001 Q_{i}-16 \leq R N_{i}, \quad i=1,2, \ldots, 9$

$\mathrm{TN}_{i}=0.06 H_{i}+0.00068 Q_{i}-15 \leq R N_{i}, \quad i=10,11, \ldots, 16$

$\mathrm{TN}_{i}=2.876-0.0001519 Q_{i} \leq R N_{i} \quad i=17,18, \ldots, 24$

$\mathrm{TN}_{i}=-0.065 H_{i}-0.00009642 I_{i}+12.669 \leq R N_{i}, \quad i=25,26, \ldots, 36$

\subsubsection{The constraints of TP.}

$\mathrm{TP}_{i}=1.605-0.0093 H_{i} \leq R P_{i}, \quad i=1,2, \ldots, 9$

$\mathrm{TP}_{i}=1.595-0.0099 H_{i} \leq R P_{i}, \quad i=10,11, \ldots, 16$

$\mathrm{TP}_{i}=0.000001292 I_{i}+0.000002168 Q_{i}-0.032 \leq R P_{i}$,

$$
i=17,18, \ldots, 24
$$

$\mathrm{TP}_{i}=0.000001341 Q_{i}-0.0031 H_{i}-0.000005329 I_{i}-0.516 \leq R P_{i}$,

$i=25,26, \ldots, 36$

3.3.2.5. Other constraints. The reservoir water balance equation

$V_{i+1}=V_{i}+\left(I_{i}-Q_{i}\right) \times T_{i}$

The constraints of water level

$Z_{\min } \leq Z\left(Q_{i}\right) \leq Z_{\max }$
The constraints of water head

$H_{\min } \leq H_{i} \leq H_{\max }$

The constraints of capacity of hydropower plant outlets

$N_{\text {min }} \leq N_{i} \leq N_{\max }$

$N_{i}=\alpha_{i} Q_{i}\left(Z_{\text {up }}\left(Q_{i}\right)-Z_{\text {down }}\left(Q_{i}\right)-Z_{\text {loss }}\right)$

where $\mathrm{DA}_{i}$ is the density of algal cell in the $i$ th period; $\mathrm{TN}_{i}$ is the total nitrogen concentrations in the $i$ th period; $\mathrm{TP}_{i}$ is the total phosphorus concentrations in the $i$ th period; $\mathrm{RDA}_{i}, \mathrm{RN}_{i}$ and $\mathrm{RP}_{i}$ are the water quality requirement for the $\mathrm{DA}$, TN and TP, respectively (Cao et al., 2011); $Z_{\min }$ is the minimal water level; $Z_{\max }$ is the maximal water level; $H_{\min }$ is the minimal water head; $H_{\max }$ is the maximal water head; $N_{\min }$ is the minimal capacity of hydropower plant outlets; $N_{i}$ is the capacity of hydropower plant outlets in the ith period; $N_{\max }$ is the maximal capacity of hydropower plant outlets. $Z_{\min }, Z_{\max }, H_{\min }, H_{\max }, N_{\min }$ and $N_{\max }$ come from the paper of the Liu et al., (2004).

\subsection{Genetic algorithm}

The real-coded improved GA with SBX and self-adaptive mutation is applied to searching for the optimal water releases and water levels of the TGR within one year based on the developed SMEROM model. A 10-day period (the traditional time range in Chinese agricultural society) is used as the basic time unit. Hence, every year has 36 periods. Accordingly, there are 36 water releases (decision variables) and 36 water levels (decision variables) that need to be optimized in each year. Table 3 shows the parameters used in the improved GA. Among them, the main parameters (population size, initial crossover rate, and initial mutation rate) are chosen based on their effects on the final fitness. The choice of final iteration number is based on the trialand-error method. The other parameters are selected based on the references (Haupt and Haupt, 2004; Hakimi-Asiabar et al., 2008; Kancev et al., 2011; Subbaraj et al., 2011; Han et al., 2012).

The GA begins with an initial population of chromosomes (solutions) being defined; a weight is given to each individual according to its fitness; parents can be selected either randomly or according to their fitness in order to generate new individuals by three operators (selection, crossover, and mutation); and then the new individuals form the new population. The GA will continually make its population evolved until the convergence criterion is reached.

\subsubsection{Initial population}

In the SMEROM, each chromosome is encoded as a vector of real numbers, with the same length as the vector of decision variables. The possible solution (water releases and water levels) of the SMEROM is defined as a chromosome. The GA begins with an initial population of $N_{\text {pop }}$ chromosomes, which can be expressed as follows:

$\mathrm{POP}=\left[C_{1}, C_{2}, C_{3}, \ldots, C_{i}\right] \quad i=1,2, \cdots N_{\text {pop }}$

Each chromosome $C_{i}$ is represented by the decision variable. A vector $C_{i}=\left[P_{i 1}, P_{i 2}, P_{i 3}, \ldots, P_{i j}\right]$ is $i$ th chromosome to represent a solution to the optimization problem. And an initial decision variable is generated as

$P_{i j}=P_{i j, \min }+\alpha_{j}\left(P_{i j, \max }-P_{i j, \min }\right)$

where $P_{i j}$, min and $P_{i j \text {, max }}$ are the lower and upper limits of $P_{i j}$, and $\alpha_{j}$ is the uniformly distributed random number in the range between 0 and 1 . 
Table 3

The parameters of genetic algorithm.

\begin{tabular}{lll}
\hline Symbol & Meaning & Value \\
\hline$N_{\text {POP }}$ & Population size & 1000 \\
$P_{c}$ & Initial crossover rate & 0.6 \\
$P_{m}$ & Initial mutation rate & 0.1 \\
$\eta_{c}$ & Distribution index & 1 \\
$k_{1}, k_{2}$ & Coefficients of mutation operator & 0.5 \\
IN & Iteration number & 250 \\
$\Delta$ & Stop criteria: the improving rate of fitness & $\leq 0.001$ \\
$P_{i j}$ & The range of water release, $j=1,2, \ldots, 36$ & {$[5000,50,000] \mathrm{m}^{3} / \mathrm{s}$} \\
& The range of water level, $j=37,38, \ldots, 72$ & {$[140,200] \mathrm{m}$} \\
\hline
\end{tabular}

\subsubsection{Selection}

The selection operation is the next step in the GA, which determines which pair of chromosomes is fit enough for creating the new offspring population. Every chromosome in the population is evaluated by the fitness function and ranked from the lowest value to the highest value (Haupt and Haupt, 2004). The ranking refrains from giving the largest share of offspring to a small group of highly fit chromosomes, and thereby the selection pressure is reduced when the fitness has a big variance. Every chromosome is assigned with a probability proportional to its ranking. The probabilities mentioned above are calculated as follows:

$P_{n}=\left(N_{\mathrm{POP}}-n+1\right) / \sum_{n=1}^{N_{\text {POP }}} n$

where $P_{n}$ is the probability of selection, $N_{\text {pop }}$ is the population size, and $n$ is the rank of the chromosome.

A uniformly distributed random number between 0 and 1 would be generated after the survived probability is determined. Starting at the top of the list, the first chromosome, with a greater cumulative probability, is selected for reproduction. The selected chromosome is then added in an empty array with the length of $N_{\text {pop }}$, which is defined as a mating pool. The selection goes on until all chromosomes from the survived population are listed. In order to complete the mating pool, the procedure is repeated until the rest of the needed parents are chosen. In the process, $N_{\text {pop }} / 2$ pairs of chromosomes are chosen for reproduction.

\subsubsection{Crossover}

The simulated binary crossover (SBX) can create two children solution from two parent solutions (Deb and Kumar, 1995). As the name suggests, the SBX operator simulates the working principle of the single point crossover operator on binary or real-number strings. Deb has demonstrated that real-parameter GAs with SBX exhibit self-adaptive behavior on a number of test problems (Deb and Beyer, 2001a). Therefore, the self-adaptive real-parameter GAs with SBX is applied in this paper (Deb, 2004; Haupt and Haupt, 2004). Based on the interval schemata processing of the SBX operator, common interval schemata between parents are preserved in children. The created offspring from two parent chromosomes would be compared with both parents, and the parents will be replaced by the offspring which has better fitness than the parent. The procedure of computing the children $c_{1}$ and $c_{2}$ from parent solutions $x_{1}$ and $x_{2}$ is described as follows. First, a random number $\mathrm{u}$ between 0 and 1 is generated. Thereafter, from a polynomial probability distribution, parameter $\beta_{q}$ is defined as follows:

$\beta_{q}= \begin{cases}(u \alpha)^{\frac{1}{\eta_{c}+1}} & , \text { if } u \leq \frac{1}{\alpha} \\ \left(\frac{1}{2-u \alpha}\right)^{\frac{1}{\eta_{c}+1}}, & \text { otherwise }\end{cases}$ where $\alpha=2-\beta^{-\left(\eta_{c}+1\right)}$, and $\beta$ is calculated using Eq. (33)

$\beta=1+\frac{2}{x_{2}-x_{1}} \min \left[\left(x_{1}-x_{l}\right),\left(x_{u}-x_{2}\right)\right]$

In Eq. (32), the distribution index $\eta_{c}$ is any nonnegative real number. A small value of $\eta_{c}$ allows solutions far away from parents to be created as children solutions, while a large value restricts only near-parent solutions to children solutions. Where the parameter $x_{1}$ or $x_{2}$ is assumed to vary in $\left[x_{1}, x_{u}\right]$. After obtaining $\beta_{q}$ from the above equation, the children solutions are then obtained as follows:

$c_{1}=0.5\left[\left(x_{1}+x_{2}\right)-\beta_{q}\left|x_{2}-x_{1}\right|\right]$

$c_{2}=0.5\left[\left(x_{1}+x_{2}\right)+\beta_{q}\left|x_{2}-x_{1}\right|\right]$

It is assumed here that $x_{1}$ is less than $x_{2}$. A simple modification to the above equation can be performed if $x_{1}$ is greater than $x_{2}$. For handling multiple decision variables $\left(x_{1}, x_{2}, \ldots x_{n}\right)$, each variable is chosen with a probability of 0.5 and the above SBX operator is applied variable by variable. In all of the simulation results, we have used $\eta_{c}=1$ (Han et al., 2012).

According to Eqs. (34) and (35), the two children solutions are symmetric to the parent solutions. In this way, any bias towards any particular solution is avoided in a single crossover operation. The SBX operator has two features: (a) children solutions are created in proportion to the difference in parent solutions and (b) children solutions closer to parent solutions are monotonically more probable. These features are essential for the search algorithm to exhibit self-adaptation, since the spread of current population affects the spread of solutions in the resulting population. In the initial population, the randomly generated solutions allow almost any values to be created as a child solution. When the chromosomes come closer, the effective variance of probability distribution in the SBX operator reduces. Gradually, the created children solutions would be not far away from each other. This helps to produce continuously closer population members, thereby producing the effect of increased precision like that in the self-adaptive ES (Deb and Beyer, 2001a).

\subsubsection{Mutation}

To avoid the destruction of good genetic material, self-adaptive mutation is applied. The mutation rate changes self-adaptively with the increase of the generation number and which is decided by the individual fitness and the overall performance of population (Kumar and Naresh, 2007)

$P_{m}= \begin{cases}\frac{k_{1}\left(f_{\max }-f^{\prime}\right)}{\left(f_{\max }-f_{\text {avg }}\right)} & f^{\prime} \geq f_{\text {avg }} \\ k_{2} & f^{\prime}<f_{\text {avg }}\end{cases}$

where $P_{m}$ is the mutation rate; $f_{\max }$ is the maximum fitness value; $f_{\text {avg }}$ is the average of all fitness value; $f^{\prime}$ is the bigger value between the parents who would make the crossover; $k_{1}$ and $k_{2}$ are fixed values, which are equal to 0.5 in this study (Srinivas and Patnaik, 1994). The mutation rate $\left(p_{m}\right)$ changes self-adaptively in order to obtain satisfying offspring based on Eq. (36). Therefore, the parents would be replaced by the mutated offspring with better fitness.

\subsubsection{Computational procedure}

The detailed computational procedure for the improved GAs is summarized in Fig. 3 and the steps are described as follows:

Step 1: The initial parameters are inputted: the population size $\left(N_{\text {pop }}\right)$ is 1000 , the initial crossover rate is 0.6 , the crossover constant $\left(\eta_{c}\right)$ is 1 , and the initial mutation rate is 0.1 . 
Step 2: The initial population (POP) is generated. The fitness values of the population are then calculated.

Step 3: Tournament selection operation is performed with a probability proportional to individual rank.

Step 4: Produce a random number from polynomial probability distribution.

Step 5: If the random number belongs to [0.5, 0.9], using the SBX crossover.

Step 6: If the random number does not belong to [0.5, 0.9], using the self-adaptive mutation.

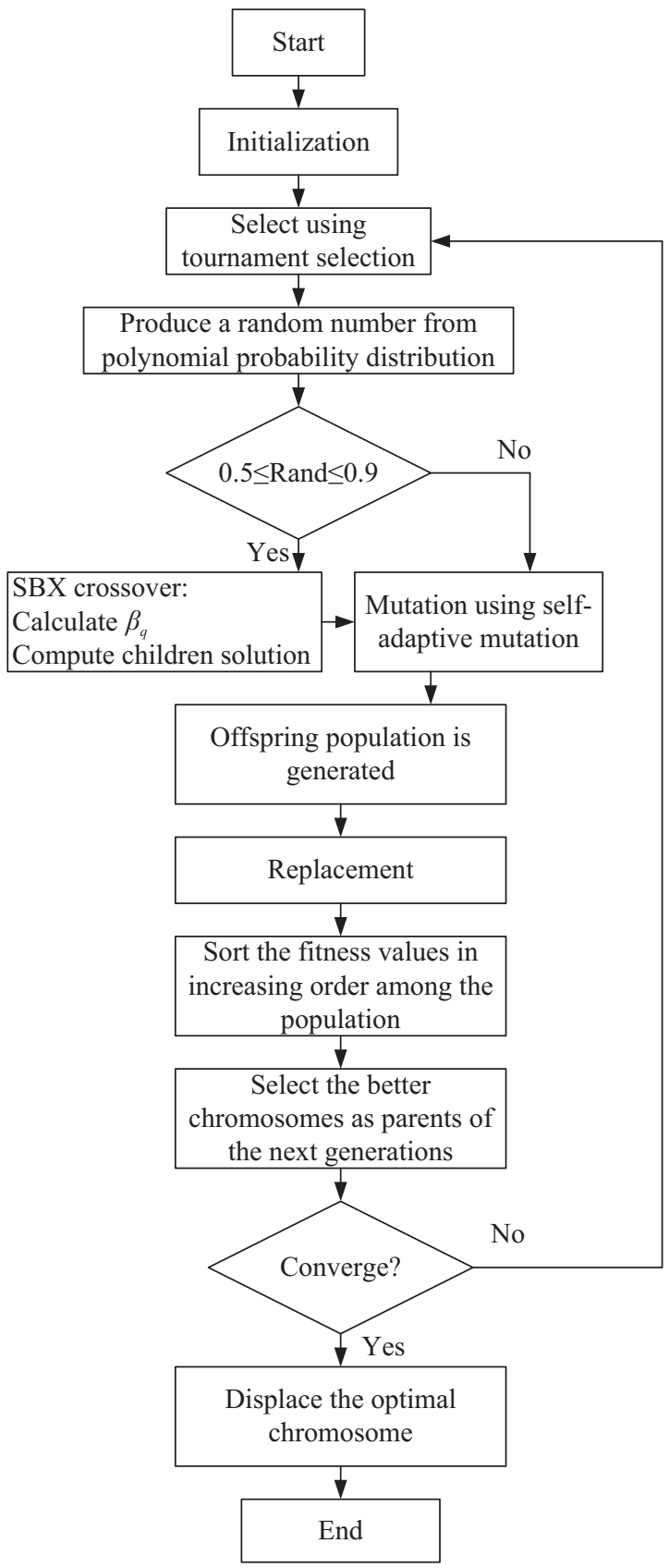

Fig. 3. The solution process for the improved GAs.
Step 7: Offspring population is generated.

Step 8: Replace the parents with the offspring with a better fitness value.

Step 9: Sort the fitness values among the generated population. Step 10: Select the better M (the number of decision variables) chromosomes as the parents in the next generation.

Step 11: Check for the stopping criteria. If the stopping condition is not met, the program goes to step 3 .

Step 12: Display the optimal chromosome and the optimal solutions.

\section{Results and discussion}

\subsection{Weights for multiple objectives}

To quantify the importance of different objective functions in the SMEROM model, the weighting method was employed. During the flood season, the flood control plays a very important role in the day-to-day running of the TGR. Considering the economic and social benefit, the weights of different objectives for hydropower generation, flood control and shipping are 0.349, 0.624 and 0.027, respectively. During the dry season, the efficiency of power generation is the most important concern than the other objectives. Therefore, the weights of hydropower generation, flood control and shipping are $0.604,0.243$ and 0.153 , respectively. The sub-objectives of the flood control (loss, rate, and capacity) share the same weight $(0.208$ in the flood season and 0.081 in the dry season).

\subsection{Statistical water quality models}

To quantify the response dependence of water quality on reservoir operation within the SMEROM framework, the multiple linear regression models were conducted between reservoir operation and three water quality indexes (TN, TP and DA). All the statistical procedures were conducted through the SPSS 15.0 for Windows. These regression equations between reservoir operation and water quality indexes were used as the constraints of the developed model (Eqs. (15-23)). The data of reservoir operation (water release, water head and inflow) were used to calibrate the statistical water quality models, which reflect the relationships between reservoir operation and water quality. Table 4 shows the correlation coefficients for calibrating the statistical water quality models.

\subsection{The process of $G A$}

To solve the complex multi-objective ecological reservoir operation problem, the SMEROM requires many decision variables to be adjusted to optimize the multiple conflicting objectives through GA. Fig. 4a shows the variation of fitness values during a representative evolution process of the improved GA. Before generation 200, the solutions in higher generations are better than those in lower generations. When the generation reaches around 200, the non-inferior solutions converge, which suggests that the improved GA method features quick convergence. Thus, generation 250 is set as the final iteration number, which is usually more than the average converging generation. Fig. 4b-d shows the effects of main parameters (population size, initial crossover rate, and initial mutation rate) on the variance of final fitness through representative GAs. It can be seen that the final fitness

Table 4

Correlation coefficients for calibrating the statistical water quality models.

\begin{tabular}{|c|c|c|c|c|c|c|c|c|c|}
\hline Equations & 15 & 16 & 17 & 18 & 19 & 20 & 21 & 22 & 23 \\
\hline Correlation coefficient $(R)$ & 0.840 & 0.872 & 0.914 & 0.864 & 0.894 & 0.903 & 0.867 & 0.835 & 0.905 \\
\hline
\end{tabular}


a

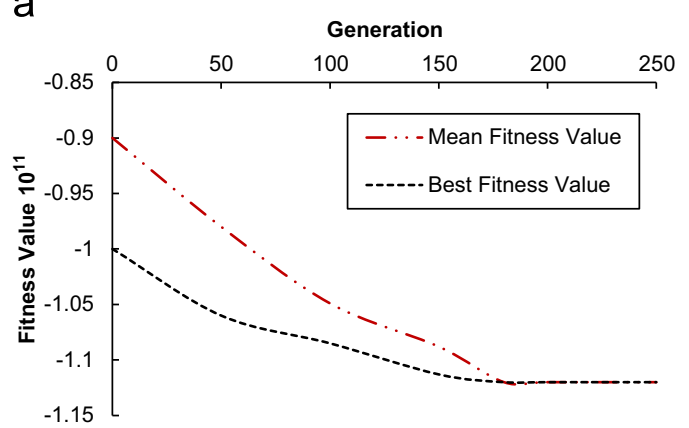

C

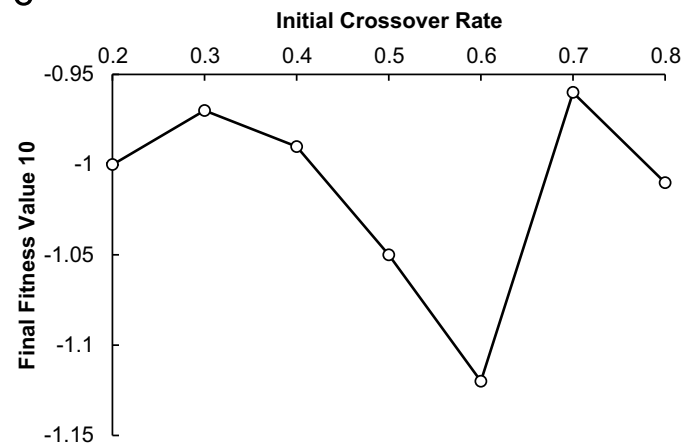

b

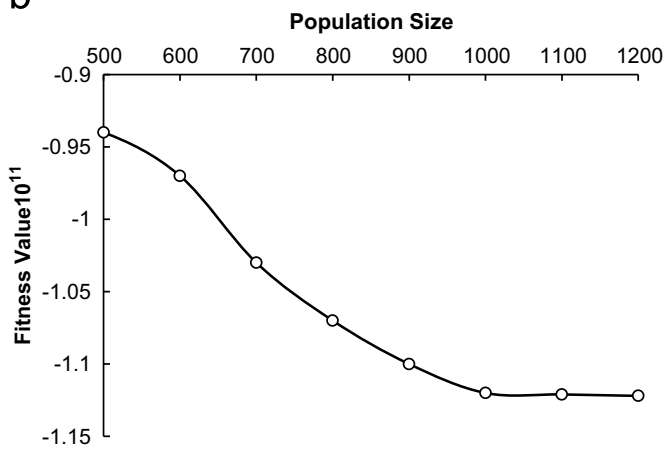

d

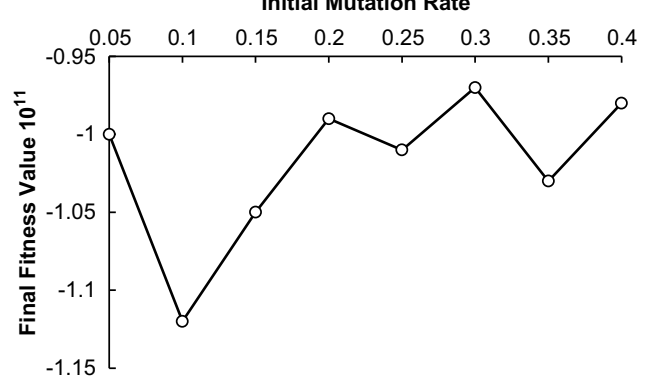

Fig. 4. Representative fitness values during the GA's evolution process under different parameters.

of GA may reach the optimal values when the population size $\left(N_{\text {pop }}\right)$ is 1000 , the initial crossover rate $\left(P_{c}\right)$ is 0.6 , and the initial mutation rate $\left(P_{m}\right)$ is 0.1 . In general, a small $N_{\text {pop }}$ may affect the diversity of the population while a larger $N_{\text {pop }}$ may bring about much more calculation. The higher the value of $p_{c}$, the quicker the new solutions generated in the population would be. However, solutions can be disrupted faster once $P_{c}$ increases although some mutation is required to prevent the premature convergence of the GA, a large value of $P_{m}$ may transform the GA into a purely random search algorithm. Overall, the entire evolution process is mainly affected by the SBX operator and the premature convergence is prevented significantly by the modified mutation operator, which shows that the improved GA can deal with the SMEROM effectively and rapidly.

\subsection{The solutions of different reservoir operations}

In order to demonstrate the advantages of ecological operation over both the traditional operation and the practical operation in 2011, the water level, water release, and water storage in the three different operations were compared respectively in Fig. 5. The traditional operation model can be obtained through removing the constraints of water quality indexes from the SMEROM, which can be solved using the same improved GA. The practical operation is the one really implemented in the TGR in 2011, which was based on the opinions from the related managers and experts. The black, red and pink lines in Fig. 5 shows the solutions of traditional operation, the practical operation in 2011, and ecological operation, respectively.

\subsubsection{The water level}

Fig. 5a shows the comparison of water level among the three different operations. In Fig. 5a, the pink line shows the relationship between water levels and periods (10 days) in the ecological operation. From the whole winter (periods $1-3$ and 32-36) to the early spring (periods 3-6), the TGR kept a high operational water level in order to achieve much more hydropower in the dry season and meet the demand for electricity. From the spring to the summer (periods 7-16), the water level started to decline gradually. From the summer to the autumn (periods 17-27), the TGR maintained the lowest water level for flood control because this stage had a high incidence of floods. The water level rose gradually in late-autumn (periods 28-31) to meet control requirements for inflow, hydropower and water quality. Compared with the ecological operation, the other two operations had similar patterns except for different declining, stable and rising stages for the water level. The declining stages for the ecological, traditional and practical operations were 11, 17 and 17 periods, respectively. The rapidly and quickly declining water level could lead to strong fluctuations of the water body and then help to restrain the phytoplankton blooms. The stable stage for ecological operation was the longest than the other operations. The rising stages for the traditional and ecological operations were similar while that for the practical operation was the longest. This was due to the different impounding requirements for water quantity and hydro-power in the dry season.

\subsubsection{The water release}

Fig. 5b shows the comparison of water release among the three different operations. In Fig. 5b, the pink line shows the water release of TGR for generating hydropower through the turbines in the ecological operation. The water release had slight fluctuations in periods $1-14$, and $32-36$. However, the water release had very drastic fluctuations in periods $15-31$. This pattern would be due to the interacted requirements for water quality in the XXR, flood control in the TGR, and electricity generation. Compared with the ecological operation, the other two operations had the similar patterns of water release in periods $1-12$ and $32-36$. The difference among the three operations mainly laid in periods 13-31. Within these periods, the ecological operation had the most drastic fluctuations than the others. This might be because this type of fluctuations could help prevent the XXR from algal bloom with high incidences. 

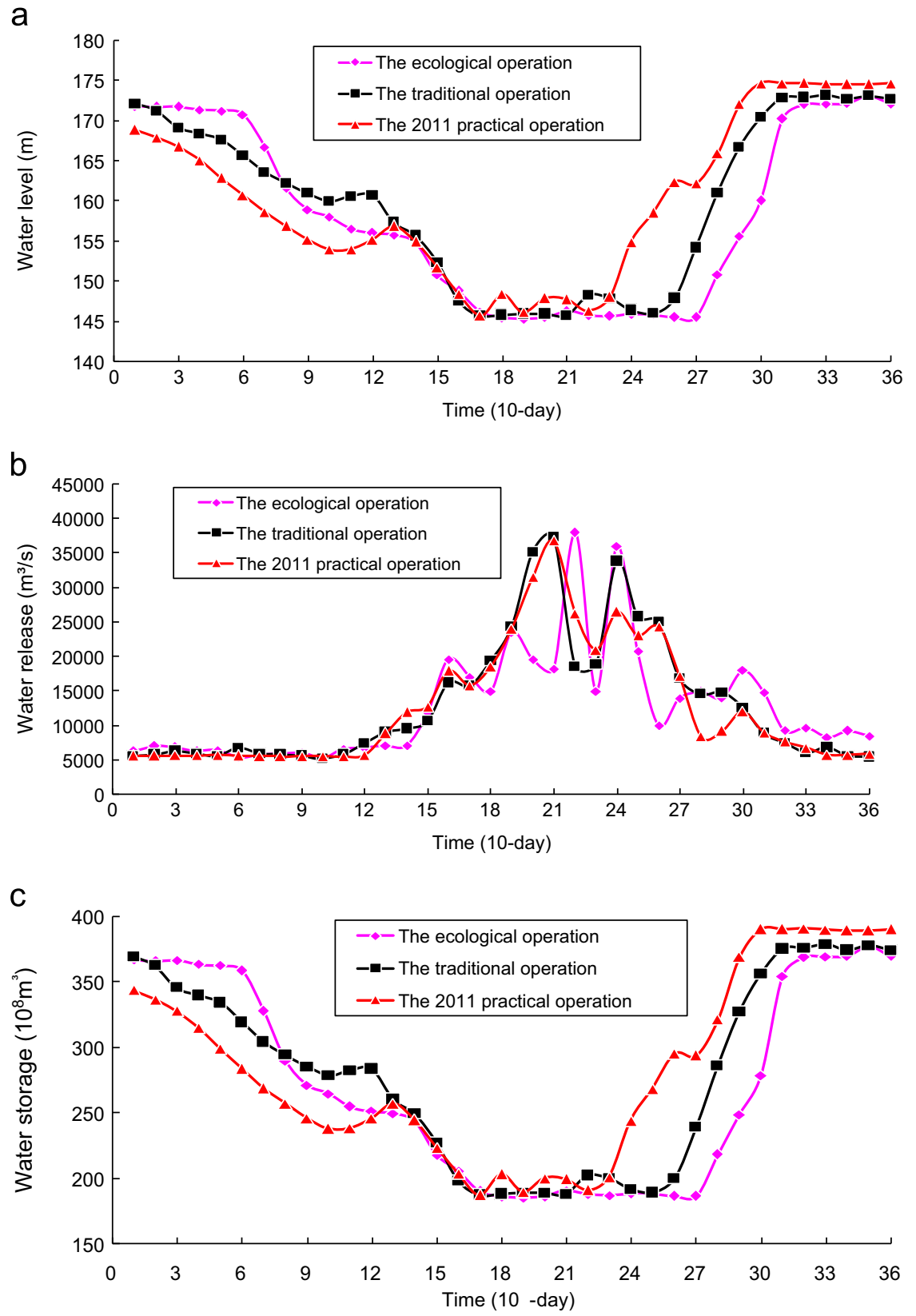

Fig. 5. The solutions of water level (a), water release (b) and water storage (c) in different reservoir operations. (For interpretation of the references to color in this figure legend, the reader is referred to the web version of this article.)

\subsubsection{The water storage of TGR}

Fig. $5 \mathrm{c}$ shows the comparison of water storage among the three different operations. As the water storage of the TGR is proportional to the water level, the water storage has a similar three-stage pattern (declining, stable and rising stages). The pink line in Fig. 5c represents the water storage of TGR in the ecological operation, which can help the TGR operator to learn the real-time water quantity information. In the spring (periods 3-12), the water storage kept declining. From the summer to the early autumn, the water storage continued declining before period 17, reached the lowest point in period 18 , and then maintained the lowest value until period 27 (to prepare for the possibly upcoming flood). From the late autumn to the winter, the water storage began to rise until the biggest value was reached. Among three operations, the water storage in the practical operation was the biggest in the winter while that in the ecological operation is the smallest. This was mainly because these operations had different lasting time for the rising stage. The practical operation had enough time to increase its storage; the very short rising stage of ecological operation with scarce water quantity led to the smallest but allowable water storage.

\subsection{Water quality in the Xiangxi river}

To evaluate the water quality responses to the three operations, the statistical water quality models were used to obtain the corresponding water quality indexes (Fig. 6). It was indicated that the ecological operation based on the developed SMEROM had obvious significant advantages in improving the water quality of the XXR, compared with the traditional and practical operations.

\subsubsection{Density of algal cell (DA)}

Fig. 6a shows the comparison of the DA in the XXR during the planning period among the three different operations. In Fig. 6a, the pink line shows the change of the DA in the ecological operation. In the spring (periods 4 to 12 ), the DA ranged from $680 \times 10^{4} / \mathrm{L}$ to 
a

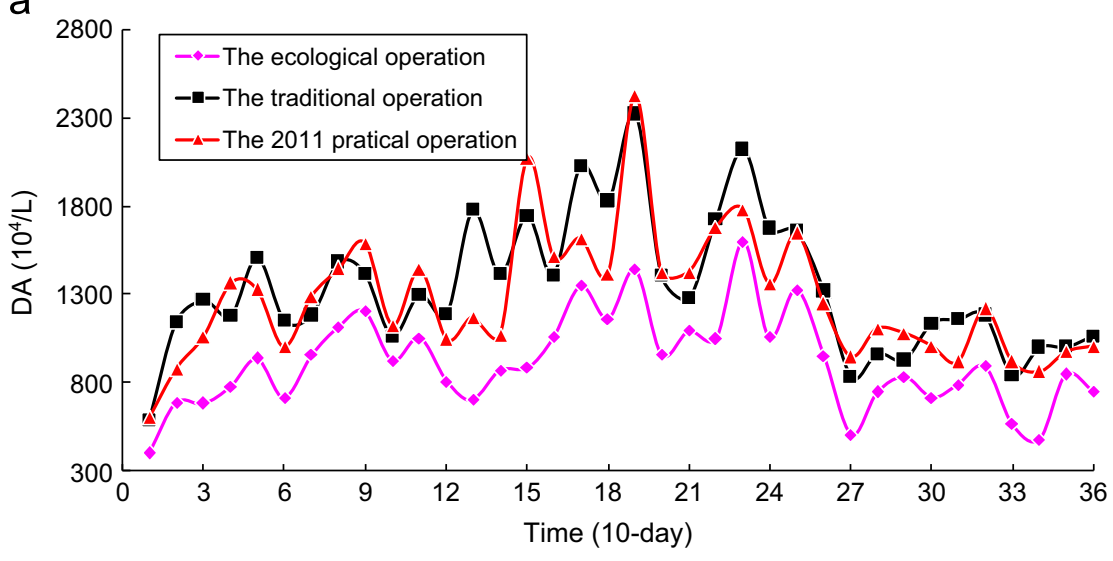

b

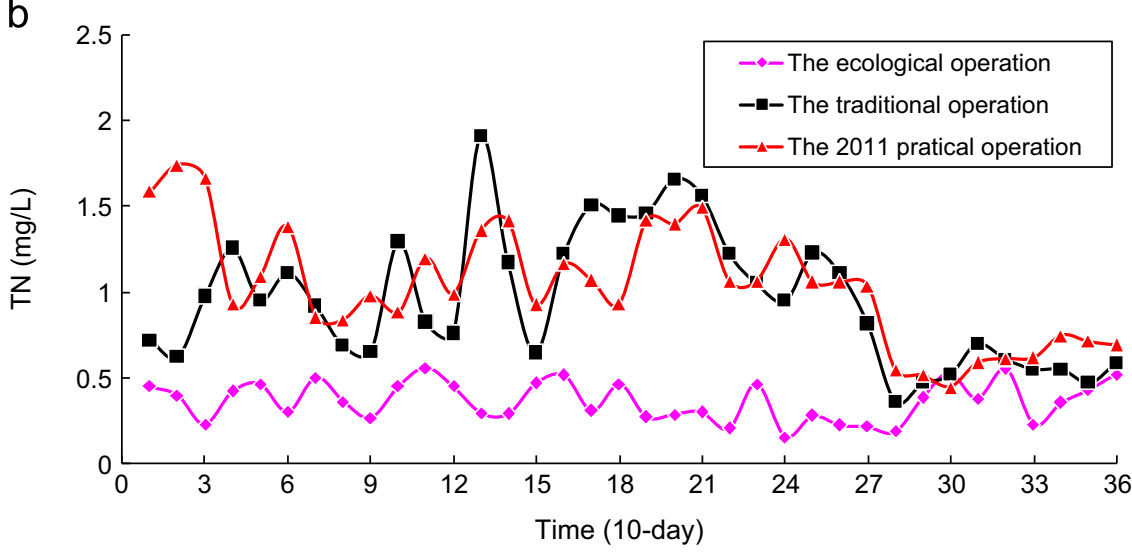

C

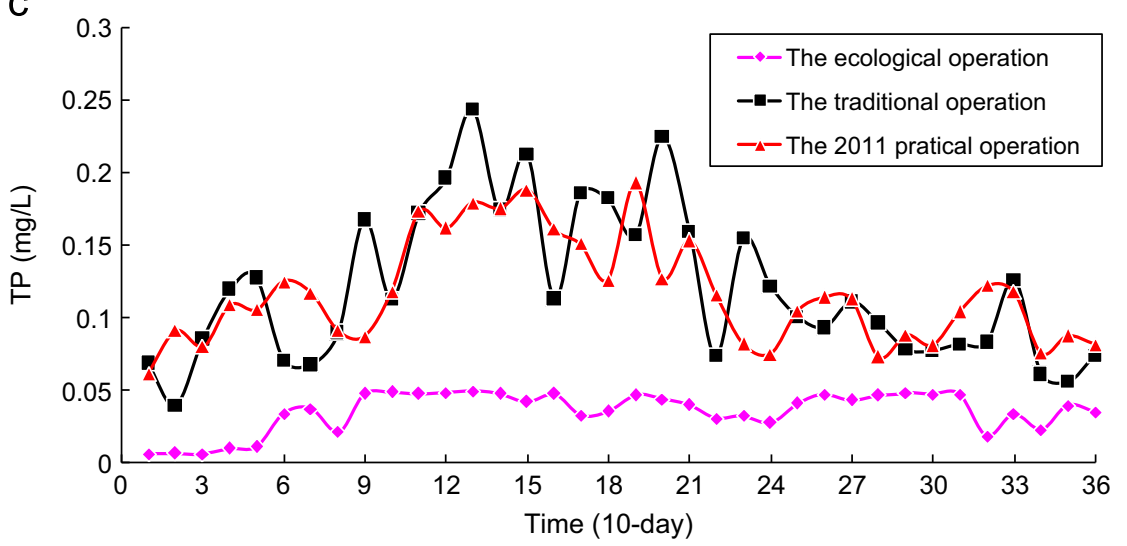

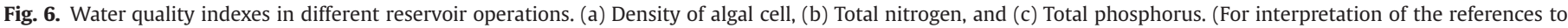
color in this figure legend, the reader is referred to the web version of this article.)

$1200 \times 10^{4} / \mathrm{L}$, which had a gradually rising trend except for periods 6 and 10. In the summer (periods 13-21), the highest value of the DA was $1450 \times 10^{4} / \mathrm{L}$ (period 19), with a higher average value being about $1150 \times 10^{4} / \mathrm{L}$. In the autumn (periods $22-31$ ), the DA had an obvious fluctuation with the highest value being $1600 \times 10^{4} / \mathrm{L}$ in period 23 (the highest peak in the ecological operation), which was still in the allowed range. In the winter (periods 32-36 and 1-3), the fluctuation of DA was very slight with the lowest average value being $650 \times 10^{4} / \mathrm{L}$. It was indicated that, besides the impacts of seasonal changes in temperature and rainfall, the water levels affected by the ecological operation might change the DA values. Compared with the ecological operation, the DA in the other two operations were much higher. The DA in the traditional and the practical operations had similar patterns and ranges. Their average values were about $500 \times 10^{4} / \mathrm{L}$ more than that in the ecological operation, which were about $300 \times 10^{4} / \mathrm{L}$ more than the allowed range. In these two operations, the fundamental target was to maximize economic benefit so that protection of the water environment might be neglected.

\subsubsection{Total nitrogen concentrations (TN)}

Fig. 6b shows the comparison of the TN among the three different operations. In Fig. 6b, the pink line presents the change of the TN in the ecological operation. The TN had an obvious wavy fluctuation in the entire year but all of the values met the local water quality standard (under $0.6 \mathrm{mg} / \mathrm{L}$ ). In some periods of the winter, the TN kept a high level so some measures should be taken to prevent possible eutrophication in the next year. Compared with the ecological operation, the $\mathrm{TN}$ in the traditional and 
practical operations were above $0.5 \mathrm{mg} / \mathrm{L}$, with the average values being $0.96 \mathrm{mg} / \mathrm{L}$ and $1.03 \mathrm{mg} / \mathrm{L}$, respectively. Therefore, the advantage of the ecological operation on improvement of TN was demonstrated. It was also indicated that (a) the fluctuations of water quantity and levels in the ecological operation could keep the TN less than a certain concentration; (b) the traditional and the practical operations might not effectively balance the relationship among hydroelectric generation, flood control and water quality.

\subsubsection{Total phosphorus concentrations (TP)}

Fig. $6 \mathrm{c}$ shows the comparison of the TP among the three different operations. In Fig. 6c, the pink line shows the change of the TP in the ecological operation. In the early spring (periods 4-5), the TP was the lowest with the average value being about $0.008 \mathrm{mg} / \mathrm{L}$. In the middle spring (periods 6-8), the TP maintained a high level but still under $0.04 \mathrm{mg} / \mathrm{L}$. In the late spring (periods 9-12) and the whole summer (periods 13 to 21), the TP was in a dangerous level (above $0.045 \mathrm{mg} / \mathrm{L}$ ). In some periods of the summer (periods 9-16) and the autumn (periods 26-31), the TP was the highest (about $0.05 \mathrm{mg} / \mathrm{L}$ ) during the year, which might cause eutrophication so that necessary measures would be applied to protect the water quality. However, these TP values were still much less than those in the traditional and practical operations. The average values in the ecological, traditional and practical operations were $0.041 \mathrm{mg} / \mathrm{L}$, $0.12 \mathrm{mg} / \mathrm{L}$ and $0.11 \mathrm{mg} / \mathrm{L}$, respectively. Therefore, the water quality improvement in the ecological operation is obvious.

\subsection{Comparison of objective function values}

Table 5 shows the different objective function values in the ecological and traditional operations. The benefit of hydropower in the traditional operation $\left(188.25 \times 10^{8} \mathrm{RMB}\right)$ was higher than that in the ecological operation $\left(153.83 \times 10^{8} \mathrm{RMB}\right)$. The loss benefit of flood control in the traditional operation $\left(77.18 \times 10^{8} \mathrm{RMB}\right)$ was also higher than that in the ecological operation $\left(55.18 \times 10^{8} \mathrm{RMB}\right)$. In comparison, the other objective functions in the ecological operation, such as the rate of flood risk (1.11\%), the average remaining capacity of flood control $\left(129.69 \times 10^{8} \mathrm{~m}^{3}\right)$ and the efficiency of shipping (96.68\%), were all superior to those in the traditional operation $\left(1.43 \%, 96.15 \times 10^{8} \mathrm{~m}^{3}\right.$ and $\left.95.60 \%\right)$. It was indicated that (a) the significant difference between the two objective function values mainly resulted from flood control and hydropower; (b) some benefit (such as the hydropower benefit) would be lost to protect the water quality in the ecological operation; (c) the ecological operation would have more advantages in flood control than the traditional operation; and (d) the benefit of water quality improvement in the ecological operation, not quantified in the economic data, should not be neglected.

Table 5

Different objective function values in ecological and traditional operations.

\begin{tabular}{|c|c|c|}
\hline \multirow[t]{2}{*}{ Objective functions } & \multicolumn{2}{|l|}{ Operation } \\
\hline & Traditional & Ecological \\
\hline Total benefit $\left(10^{8} \mathrm{RMB}\right)$ & 111.07 & 98.65 \\
\hline The benefit of hydropower $\left(10^{8} \mathrm{RMB}\right)$ & 188.25 & 153.83 \\
\hline The loss benefit of flood control $\left(10^{8} \mathrm{RMB}\right)$ & 77.18 & 55.18 \\
\hline The rate of flood risk & $1.43 \%$ & $1.11 \%$ \\
\hline $\begin{array}{l}\text { The average remaining capacity of flood control } \\
\qquad\left(10^{8} \mathrm{~m}^{3}\right)\end{array}$ & 96.15 & 129.69 \\
\hline The efficiency of shipping & $95.60 \%$ & $96.68 \%$ \\
\hline
\end{tabular}

\section{Conclusion}

This study proposes a self-adaptive GA-aided multi-objective ecological reservoir operation model (SMEROM) and applies it to water quality management in the Xiangxi River near to the Three Gorges Reservoir, China. The SMEROM integrates statistical water quality models, multi-objective reservoir operations, and a selfadaptive GA within a general framework. Among them, the statistical water quality models of the Xiangxi River have been formulated to deal with the relationships between reservoir operation and water quality. The statistical models, based on multiple linear regression and Pearson correlation analysis, are embedded in constraints of the SMEROM. The multiple objective functions, including maximizing hydropower generation, minimizing loss of flood control, minimizing rate of flood risk, maximizing the average remaining capacity of flood control and maximizing the benefit of shipping, have been considered simultaneously to obtain comprehensive benefit among the environment, society and economy. The weighting method is employed to convert the multiple objectives to a single objective. To solve the complex SMEROM, an improved self-adaptive GA is employed through incorporating simulated binary crossover and selfadaptive mutation. The GA has the advantages of fast iteration and stable convergence, which provides an adequate, effective, and robust way for searching reasonable reservoir operation schemes.

To demonstrate the advantage of the developed SMEROM model, the solutions through ecological reservoir operation have been compared with those through the traditional reservoir operation and the practical operation in 2011, in terms of water quality, reservoir operation and objective function values. The results show that most of benefit in the ecological operation is better than that in the traditional or practical operations except for the hydropower benefit and the loss benefit of flood control. This is because flood control and environmental protection are reasonably considered in the ecological operation. The SMEROM can help decision-makers to analyze the tradeoff between the objective functions and environmental constraints and to evaluate alternative ecological operating rules efficiently. In the future study, uncertain models can be included to deal with uncertainties in water environmental information. In addition, more efficient algorithms should be further enhanced to handle such multiobjective reservoir operation problems.

\section{Acknowledgments}

This research was supported by the the National key scientific and technological projects of the PRC "Research and demonstration of key technologies of joint operation of multi-reservoirs based on water environment improvement of the Three Gorges reservoir and its lower reaches (2014ZX07104-005)", the Natural Sciences Foundation (51190095, 51225904), the National Basic Research Program (2013CB430401), the Program for Innovative Research Team in University (IRT1127), the 111 Project (B14008) and the Natural Science and Engineering Research Council of Canada. We are deeply grateful to the reviewers for their comments and suggestions, which have greatly helped improve the paper.

\section{References}

Ahmed, J.A., Sarma, A.K., 2005. Genetic algorithm for optimal operating policy of a multipurpose reservoir. Water Resour. Manag. 19 (2), 145-161.

Augusto, O.B., Rabeau, S., Depince, Ph., Bennis, F., 2006. Multi-objective genetic algorithms: a way to improve the convergence rate. Eng. Appl. Artif. Intell. 19, 501-510. 
Cabecinha, E., Cortes, R., Miguel, A.P., 2009. A Stochastic Dynamic Methodology (StDM) for reservoir's water quality management: validation of a multi-scale approach in a south European basin (Douro, Portugal). Ecol. Indic. 9, 329-345.

Cai, X., McKinney, D.C., Lasdon, L.S., 2001. Solving nonlinear water management models using a combined genetic algorithm and linear programming approach. Adv. Water Resour. 24 (6), 667-676.

Cai, Q.H., Hu, Z.Y., 2006. Studies on eutrophication problem and control strategy in the Three Gorges Reservoir (in Chinese). Acta Hydrobiol. Sin. 30 (1), 7-11.

Camdevyren, H., Demyr, N., Kanik, A., Keskyn, S., 2005. Use of principal component scores in multiple linear regression models for prediction of Chlorophyll-a in reservoirs. Ecol. Model. 181, 581-589.

Cao, C.J., Zheng, B.H., Chen, Z.L., Huang, M.S., Zhang, J.L., 2011. Eutrophication and algal blooms in channel type reservoirs: a novel enclosure experiment by changing light intensity. J. Environ. Sci. 23 (10), 1660-1670.

Castelletti, A., Galelli, S., Restelli, M., Soncini-Sessa, R., 2012. Data-driven dynamic emulation modelling for the optimal management of environmental systems. Environ. Model. Softw. 34, 30-43.

Chang, L.C., 2008. Guiding rational reservoir flood operation using penalty-type genetic algorithm. J. Hydrol. 354, 65-74.

Chang, L.C., Chang, F.J., Wang, K.W., Dai, S.Y., 2010. Constrained genetic algorithms for optimizing multi-use reservoir operation. J. Hydrol. 390, 66-74.

Chaves, P., Chang, F.J., 2008. Intelligent reservoir operation system based on evolving artificial neural networks. Adv. Water Resour. 31, 926-936.

Chen, L., McPhee, J., Yeh, W.W-G., 2007. A diversified multi-objective GA for optimizing reservoir rule curves. Adv. Water Resour. 30, 1082-1093.

Chen, Q.W., Yang, Q.R., Lin, Y.Q., 2011. Development and application of a hybrid model to analyze spatial distribution of macroinvertebrates under flow regulation in the Lijiang River. Ecol. Inform. 6, 407-413.

Chen, Y., 2004. Effect of the Three Gorge Project on the sustainable development in the Yangtze River basin. Resour. Environ. Yangtze Basin 13, 109-113.

Chen, Y.H., Chang, F.J., 2009. Evolutionary artificial neural networks for hydrological systems forecasting. J. Hydrol. 367, 125-137.

Chien, H.K., Wang, S.F., 2011. Precast production scheduling using multi-objective genetic algorithms. Expert Syst. Appl. 38, 8293-8302.

Dai, H.C., Zheng, T.G., Liu, D.F., 2010. Effects of reservoir impounding on key ecological factors in the Three Gorges Region. Procedia Environ. Sci. 2, 15-24.

Deb, K., Beyer, H.G., 1999. Self-adaptation in real parameter genetic algorithms with simulated binary crossover. Proc. Genetic Evol. Comput. Conf. Morgan Kaufmann, 172-179.

Deb, K., Beyer, H.G., 2001a. Self-adaptive genetic algorithms with simulated binary crossover. Evol. Comput. 9 (2), 197-221.

Deb, K., 2004. Multi-Objective Optimization Using Evolutionary Algorithms. John Wiley \& Sons, Ltd., Chi-chester, England.

Deng, C.G., Gong, L., 2007. The study on the trend of eutrophication in the Three Gorges Reservoir (in Chinese). J. Agro-Environ. Sci. 26, 279-282.

Dong, Q.J., Wang, X.J., Ji, H., Wang, J.P., 2007. Multi-objective decision making evaluation model for floodwater utilization in three Gorges Reservoir. Resour. Environ. Yangtzi Basin 2 (16), 260-264 (in Chinese).

Fu, B., Wu, B., Lu, Y., Xu, Z., Cao, J., Niu, D., Yang, G., Zhou, Y., 2010. Three Gorges project: efforts and challenges for the environment. Progr. Phys. Geogr. 34, $741-754$.

Hakimi-Asiabar, M., Ghodsipour, S. H., Seifi, A., Kerachian, R., O'Brien, C., 2008. A multi-objective hybrid gradient-based genetic algorithm, In: Proceedings of the Fifteenth International Working Seminar on Production Economics, Innsbruck, Austria, March 3-7, pp, 235-251.

Hakimi-Asiabar, M., Ghodsypour, S.H., Kerachian, R., 2009. Multi-objective genetic local search algorithm using Kohonen's neural map. Comput. Ind. Eng. 56, 1566-1576.

Hakimi-Asiabar, M., Ghodsypour, S.H., Kerachian, R., 2010. Deriving operating policies for multi-objective reservoir systems: application of self- learning genetic algorithm. Appl. Soft Comput. 10 (4), 1151-1163.

Han, J.C., Huang, G.H., Zhang, H., Zhuge, Y.S., He, L., 2012. Fuzzy constrained optimization of eco-friendly reservoir operation using self-adaptive genetic algorithm: a case study of a cascade reservoir system in the Yalong River, China. Ecohydrology 5 (6), 768-778.

Haupt, R.L., Haupt, S.E., 2004. Practical genetic algorithms. John Wiley \& Sons, Ltd., Hoboken, New Jersey, USA.

Holland, J.H., 1975. Adaptation in Natural and Artificial Systems. The University of Michigan Press, Ann Arbor, MI.

Hu, Z., Cai, Q., 2006. Preliminary report on aquatic ecosystem dynamics of the Three Gorges Reservoir before and after impoundment. Acta Hydrobiol. Sin. 30, 1-6 (in Chinese with English abstract).

Huang, W.C., Yuang, L.C., Lee, C.M., 2002. Linking genetic algorithm with stochastic dynamic programming to the long-term operation of multi-reservoir system. Water Resour. Res. 38 (12), 1304.

Huang, Z., 2004. Eco-environmental Monitoring and Protection for the Three Gorges Project. Three Gorges of China Press, Beijing p. 2003.

Huang, Z., Li, Y., Chen, Y., Li, J., Xing, Z., Ye, M., Li, J., Lü, P., Li, C., Zhou, X., 2006. Water Quality Prediction and Water Environmental Carrying Capacity Calculation for Three Gorges Reservoir. China Water-Power Press, Beijing (in Chinese with English abstract).

Janga Reddy, M., Nagesh Kumar, D., 2006. Optimal reservoir operation using multiobjective evolutionary algorithm. Water Resour. Manag. 20, 861-878.

Janga Reddy, M., Nagesh Kumar, D., 2007. Multi-objective differential evolution with application to reservoir system optimization. J. Comput. Civ. Eng. 21 (2) 136-146.
Jiang, L.G., Yu, X.B., Li, L.F., 2006a. In: Smits, A.J.M., Nienhuis, P.H., Leuven, R.S.E.W. (Eds.), New Approaches to River Management. Science Press, Beijing, China.

Jiang, T., Zhang, Q., Zhu, D., Wu, Y., 2006b. Yangtze floods and droughts (China) and teleconnections with ENSO activities (1470-2003). Quat. Int. 144, 29-37.

Kancev, D., Gjorgiev, B., Cepin, M., 2011. Optimization of test interval for ageing equipment: a multi-objective genetic algorithm approach. J. Loss Prev. Process Ind. $24,397-404$.

Kerachian, R., Karamouz, M., 2007. A stochastic conflict resolution model for water quality management in reservoir-river systems. Adv. Water Resour. 30 (4), 866-882.

Kong, F.X., Fao, G., 2005. Hypothesis on cyan bacteria bloom-forming mechanism in large shallow eutrophic lakes (in Chinese). Acta Ecol. Sin. 25 (3), 589-595.

Krolová, M., Hana, C., Josef, H., 2012. Depth limit of littoral vegetation in a storage reservoir: a case study of Lipno Reservoir (Czech Republic). Limnologica 42 (2), $165-174$.

Kumar, S., Naresh, R., 2007. Efficient real coded genetic algorithm to solve the nonconvex hydrothermal scheduling problem. Int. J. Electr. Power Energy Syst. 29, $738-747$.

Labadie, J.W., 2004. Optimal operation of multi-reservoir systems: state-of-the-art review. J. Water Resour. Plan. Manag.-ASCE 130 (2), 93-111.

Li, C.M., Huang, Z.L., Zhang, S., 2007. Risk forecast of algal bloom in the Three Gorges Reservoir (in Chinese). Resour. Environ. Yangtze Basin 16 (1), 1-6.

Li, R.N., Chen, Q.W., Chen, D., 2010a. Application of genetic algorithm to improve the fuzzy logic river habitat model. In: Proceedings of the 6th ISEH Conference, Athens, Greece.

Li, S.Y., Li, J., Zhang, Q.F., 2011. Water quality assessment in the rivers along the water conveyance system of the Middle Route of the South to North Water Transfer Project (China) using multivariate statistical techniques and receptor modeling. J. Hazard. Mater. 195, 306-317.

Li, Y.H., Zhou, J.Z., Zhang, Y.C., Qin, H., Liu, L., 2010b. Novel multi-objective shuffled frog leaping algorithm with application to reservoir flood control operation. Water Resour. Plan. Manag. 2 (136), 217-226.

Liu, D.H., Li, N., Chao, Y., 2008. SPSS15.0 for Windows from a Beginner to a Master. Tsinghua University Press, Beijing.

Liu, P., Guo, S.L., Wang, C.J., Zhou, F., 2004. Optimization of limited water level in flood season and impounding scheme for reservoir in three gorges project. J. Hydraul. Eng. 7, 86-91 (in Chinese).

Liu, P., Guo, S.L., Pang, B., Wang, C.J., Zhang, H.G., 2006. A modified approach for deriving storage operating rules of the Three Gorges Reservoir with artificial neural network. J. Hydroelectr. Eng. 2 (25), 83-89 (in Chinese).

Liu, P., Guo, S.L., Luo, Z., Liu, X.Y., 2007. Optimization of reservoir operation by using dynamic programming-genetic algorithm. Eng. J. Wuhan Univ. 5 (40), 1-6 (in Chinese).

Lu, S.L., Wu, B.F., Wang, H., Ouyang, N.L., Guo, S.Y., 2012. Hydro-ecological impact of water conservancy projects in the Haihe River Basin. Acta Oecolog 44, 67-74.

Maillard, P., Santos, N.A.P., 2008. A spatial-statistical approach for modeling the effect of non-point source pollution on different water quality parameters in the Velhas river watershed-Brazil. J. Environ. Manag. 86, 158-170.

Mehrdad, H.A., Seyyed, H.G., Reza, K., 2010. Deriving operating policies for multiobjective reservoir systems: application of self-learning genetic algorithm. Appl. Soft Comput. 10, 1151-1163.

Mukand, S.B., Chien, N.D., Mullick, M.RA., Umamahesh, V.N., 2012. Operation of a hydropower system considering environmental flow requirements: a case study in La Nga river basin, Vietnam. J. Hydro-Environ. Res 6 (1), 63-73.

Mukhopadhyay, B., Smith, H., E., 2000. Comparison of statistical methods for estimation of nutrient load to surface reservoirs for sparse data set: application with a modified model for phosphorus availability. Water Resour. 12 (34), 3258-3268.

Rohdea, S., Hostmannb, M., Peter, A., Ewald, K.C., 2006. Room for rivers: an integrative search strategy for floodplain restoration. Landsc. Urban Plan. 78, $50-70$.

Singh, K.P., Malik., A., Sinha, S., 2005. Water quality assessment and apportionment of pollution sources of Gomti river (India) using multivariate statistical techniques-a case study. Anal. Chim. Acta 538, 355-374.

Srinivas, M., Patnaik, L.M., 1994. Adaptive probabilities of crossover and mutation in genetic algorithms. IEEE Trans. Syst. Man Cybern. 24 (4), 656-667.

Su, C.T., Chiang, C.L., 2004. An incorporated algorithm for combined heat and power economic dispatch. Electr. Power Syst. Res. 69 (2-3), 187-195.

Subbaraj, P., Rengaraj, R., Salivahanan, S., 2011. Enhancement of self-adaptive realcoded genetic algorithm using Taguchi method for economic dispatch problem. Appl. Soft Comput. 11 (1), 83-92.

Suen, J.P., Eheart, J.W., 2006. Reservoir management to balance ecosystem and human needs: incorporating the paradigm of the ecological flow regime. Water Resour. Res. 42, W03417.

Tripathi, P.K., Pal, S.K., 2007. Adaptive multi-objective particle swarm optimization algorithm. In: Proceedings of IEEE Congress on Evolutionary Computation, IEEE Computer Society, N.J, pp. 2281-2288.

Tullos, D., 2009. Assessing the influence of environmental impact assessments on science and policy: an analysis of the Three Gorges project. J. Environ. Manag. 90, S208-S223.

Vascan, A., Raju, K.S., 2009. Comparative analysis of simulated annealing, simulated quenching and genetic algorithms for optimal reservoir operation. Appl. Soft Comput. 9, 274-281.

Wang, C.J., Guo, S.L., Liu, P., Tian, X.G., 2004. Analysis of uncertainty of three Gorges Reservoir operation during flood seasons. Hydropower Autom. Dam Monitor. 2 (28), 71-74 (in Chinese). 
Wang, H., Yang, Z., Saito, Y., Liu, J.P., Sun, X., 2006. Inter-annual and seasonal variation of the Huanghe (Yellow River) water discharge over the past 50 years: connections to impacts from ENSO events and dams. Glob. Planet. Change 50 (3-4), 212-225.

Wang, K.W., Chang, L.C., Chang, F.J., 2011. Multi-tier interactive genetic algorithms for the optimization of long-term reservoir operation. Adv. Water Resour. 34 1343-1351.

Yang, Z.J., Liu, D.F., Ji, D.B., Xiao, S.B., 2010. Influence of the impounding process of the Three Gorges Reservoir up to water level $172.5 \mathrm{~m}$ on water eutrophication in the Xiangxi Bay. Technolog. Sci. 4 (53), 1114-1125.

Yandamuri, S.R.M., Srinivasan, K., Bhallamudi, S.M., 2006. Multi-objective optimal waste load allocation models for rivers using non-dominated sorting genetic algorithm-II. J. Water Resour. Plan. Manag.-ASCE 132 (3), 133-143.

Yeh, W. W-G., Becker, L., 1982. Multi-objective analysis of multi-reservoir operations. Water Resour. Res. 18 (5), 1326-1336.
Yin, X.A., Yang, Z.F., 2011. Development of a coupled reservoir operation and water diversion model: Balancing human and environmental flow requirements. Ecol. Model. 222, 224-231.

Zeilhofer, P., Rubem, M.D.M., 2009. Hydrological changes in the northern Pantana caused by the Manso dam: Impact analysis and suggestions for mitigation. Ecol. Eng. 35, 105-117.

Zeng, H., Yang, X.W., Meng, S.Y., Wang, H., Tang, X.J., Tang, W., Zeng, S., Jeschke, S., Wang, Y., 2010. Awareness and knowledge of schistosomiasis infection and prevention in the "Three Gorges Dam" reservoir area: a cross-sectional study on local residents and health personnel. Acta Trop. 120, 238-244.

Zhang, Q.F., Lou, Z.P., 2011. The environmental changes and mitigation actions in the Three Gorges Reservoir region, China. Environ. Sci. Policy 14, 1132-1138.

Zheng, B.H., Cao, C.J., Qin, Y.W., 2008. Analysis of nitrogen distribution characters and their sources of the major input rivers of the Three Gorges Reservoir (in Chinese). Environ. Sci. 29 (1), 1-6. 